\title{
RELAÇÕES ÁGUA-SOLO-PLANTA-ATMOSFERA
}

\author{
DEFICIÊNCIA HÍDRICA EM VÁRIOS ESTÁDIOS \\ DE DESENVOLVIMENTO DA BATATA ${ }^{1}$
}

\author{
Francisco Marcus Lima Bezerra², Luís Roberto Angelocci ${ }^{3}$ \\ e Keigo Minami ${ }^{4}$
}

\begin{abstract}
RESUMO
O presente estudo objetivou avaliar o comportamento da cultivar de batata (Solanum tuberosum L.) Monalisa, submetida a déficit hídrico em diferentes estádios fenológicos. O experimento foi conduzido em condições de campo, no município de Piracicaba, SP. Adotou-se o delineamento experimental de blocos ao acaso, com oito tratamentos e quatro repetições; os tratamentos consistiram na indução de déficit hídrico em um ou mais estádios fenológicos e foram iniciados 15 dias após a emergência da cultura. O estádio de tuberização foi o mais sensível ao déficit hídrico, ocorrido apenas neste, com redução da produtividade de $48,7 \%$ em relação à testemunha. A deficiência hídrica aplicada seqüencialmente nos estádios de tuberização e enchimento de tubérculos provocou redução acentuada na produtividade $(65,4 \%)$ e, quando aplicada nos três estádios, causou drástica redução na produtividade (70,5\%) em relação à testemunha. O déficit hídrico afetou também o tratamento e o número de tubérculos por planta.
\end{abstract}

Palavras-chave: Solanum tuberosum, evapotranspiração, balanço hídrico

\section{WATER DEFICIT AT VARIOUS STAGES OF DEVELOPMENT OF THE POTATO}

\begin{abstract}
Research was conducted under field conditions in the Piracicaba, SP, Brazil, to evaluate potato (Solanum tuberosum L.) "Monalisa" subjected to water deficit at different development stages. The experimental design consisted of completely randomized blocks, with eight treatments and four replications. Treatments consisted i of applying water stress at one or more development stages, starting 15 days after emergancy. Tuber formation stage, the most sensible one to water stress, had a $48.7 \%$ yield reduction in relation to the control. Water stress applied to the stages of, tuber initiation and tuber filling provided a sharp $(65.4 \%)$ yield reduction. When applied to the three stages, water stress provided a drastic $(70.5 \%)$ yield reduction. Water deficit also affected the number of tubers per plant and the tuber sizes.
\end{abstract}

Key words: Solanum tuberosum, evapotranspiration, water balance

\section{INTRODUÇÃO}

A produção eficiente e altos rendimentos de uma espécie vegetal dependem, além do potencial genético, das condições climáticas e edáficas. Referente às condições climáticas, a disponibilidade hídrica tem efeito sobre a cultura, pois a falta d'água pode afetar tanto o desenvolvimento e o crescimento quanto a produtividade e a qualidade da produção; entretanto, o conhecimento apenas da necessidade total d'água pela cultura não implica num eficiente manejo da irrigação, sendo

\footnotetext{
${ }^{1}$ Parte da tese de Doutorado defendida na ESALQ, Piracicaba, SP

${ }^{2}$ Professor, Doutor, Departamento de Engenharia Agrícola/UFC, CP 12.168, 60450-760, Fortaleza, CE

${ }^{3}$ Professor, Doutor, Departamento de Física e Meteorologia/ESALQ/USP, CP 9, 13418-900, Piracicaba, SP

${ }^{4}$ Professor, PhD, Departamento de Horticultura/ESALQ/USP, CP 9, 13418-900, Piracicaba, SP
} 
imprescindível, portanto, o conhecimento das necessidades hídricas da cultura nos diferentes estádios ou fases fenológicas do seu ciclo.

O conhecimento dos períodos críticos do desenvolvimento das culturas possibilita a adoção de práticas de manejo que visem à otimização da irrigação, alcançada através da aplicação da lâmina de irrigação certa e no estádio da cultura que apresente maior potencial de resposta (Cunha \& Bergamaschi, 1992).

A disponibilidade da água no solo é um dos fatores ambientais de efeito mais marcante no desenvolvimento da cultura da batata. $\mathrm{O}$ crescimento e o rendimento são sensíveis ao estresse hídrico (Doorenbos \& Kassam, 1979; Loon, 1981; Miller \& Martin, 1987; Jana et al., 1989) principalmente devido ao sistema radicular muito superficial. Durante o ciclo, o uso de água pela batata aumenta durante o estádio vegetativo, atingindo o máximo no início de enchimento dos tubérculos e permanecendo relativamente estático durante este estádio, reduzindo em seguida, na maturação.

A literatura apresenta vários trabalhos sobre déficit hídrico imposto em apenas um estádio fenológico da batata e, praticamente, não se dispõe de informações sobre o efeito do déficit hídrico em mais de um estádio durante o ciclo da cultura.

O objetivo deste trabalho foi estudar o comportamento da cultivar Monalisa, quando submetida a regime de déficit hídrico em estádios fenológicos, visando à quantificação da produtividade e à geração de subsídios para um adequado regime de irrigação.

\section{MATERIAL E MÉTODOS}

O trabalho foi conduzido durante o segundo semestre do ano agrícola 1993, na área experimental da USP - Escola Superior de Agricultura "Luiz de Queiroz", Departamento de Horticultura, em Piracicaba, SP (Lat. 22 42'S, Long. 47 38' O, Alt. 540m). O clima da região, de acordo com a classificação de Köppen, é tipo Cwa e o solo é classificado como Latossolo roxo, bem drenado, Série Luiz de Queiroz (Ranzani et al., 1966). As características físico-hídricas e químicas do solo da área experimental estão nas Tabelas 1 e 2.

Tabela 1. Características físico-hídricas do solo

\begin{tabular}{lccc}
\hline \multicolumn{1}{c}{ Características } & \multicolumn{3}{c}{ Camada (m) } \\
\cline { 2 - 4 } & $0-15$ & $15-30$ & $30-45$ \\
\hline Granulometria & 37,64 & 23,52 & 22,08 \\
Areia (\%) & 32,84 & 14,14 & 16,98 \\
Silte (\%) & 29,53 & 62,34 & 60,94 \\
Argila (\%) & Barrento & Argiloso & Argiloso \\
Classificação textural & 1.365 & 1.526 & 1.425 \\
Densidade do solo (kg.m $\left.{ }^{-3}\right)$ & & & \\
\hline
\end{tabular}

Tabela 2. Características químicas do solo da área experimental na camada $0-20 \mathrm{~cm}$

\begin{tabular}{|c|c|c|c|c|c|c|c|c|c|}
\hline $\mathrm{pH}$ & $P$ res. & M.O. & $\mathrm{Ca}^{2+}$ & $\mathrm{Mg}^{2+}$ & $\mathrm{K}^{+}$ & $\mathrm{H}^{+}+\mathrm{Al}^{3+}$ & CTC & $\mathrm{S}$ & V \\
\hline $\mathrm{CaCl}_{2}$ & $\mathrm{Mg} \cdot \mathrm{dm}^{-3}$ & g.dm ${ }^{-3}$ & & & 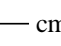 & $10 l_{c} \cdot \mathrm{dm}^{-3}$ & & & $\%$ \\
\hline 5,75 & 460,50 & 26,70 & 4,41 & 1,30 & 0,65 & 2,71 & 9,08 & 6,36 & 70,0 \\
\hline
\end{tabular}

Os dados experimentais relativos à produtividade de tubérculos foram obtidos do ensaio de campo com a cultivar Monalisa, em área cultivada de $1350 \mathrm{~m}^{2}$, sendo que as parcelas experimentais foram instaladas em duas áreas contíguas de $42 \mathrm{~m}$ x 4,6m cada uma, sob abrigo com cobertura móvel de plástico transparente de polietileno, de 200 micra de espessura, usados para proteger as parcelas da chuva. $\mathrm{O}$ delineamento experimental adotado foi o de blocos ao acaso, com quatro repetições e oito tratamentos. A unidade experimental foi constituída por cinco linhas de $2,1 \mathrm{~m}$ de comprimento, espaçadas entre si de $0,8 \mathrm{~m}$, em que cada parcela ocupou uma área de $8,4 \mathrm{~m}^{2}$, com total de 30 plantas por parcela. A área útil da parcela foi constituída pelas três linhas centrais, onde foram realizadas as avaliações de produtividade e umidade do solo, enquanto os tratamentos foram definidos em função da época de indução do déficit hídrico nos estádios vegetativo, de tuberização e de enchimento de tubérculos, aplicando-se os seguintes tratamentos: (1) testemunha, sem déficit hídrico; (2) com déficit hídrico no estádio enchimento de tubérculos; (3) com déficit no estádio de tuberização; (4) com déficit nos estádios de tuberização e enchimento de tubérculos; (5) com déficit no estádio vegetativo; (6) com déficit nos estádios vegetativo e enchimento de tubérculos; (7) com déficit nos estádios vegetativo e de tuberização e (8) nos três estádios fenológicos. Os estádios fenológicos foram definidos de acordo com o critério adotado por Kleinkopf (1983) para a batata enquanto a identificação do início dos estádios de tuberização e enchimento de tubérculos foi feita por inspeção em plantas cultivadas em volta das parcelas experimentais, a partir dos vigésimo e quatragésimo dias após a emergência da cultura, respectivamente.

$\mathrm{O}$ déficit hídrico correspondeu à aplicação da metade da lâmina média de irrigação aplicada ao tratamento sem déficit hídrico, calculada a partir do monitoramento do potencial matricial de água no solo, nas profundidades de 10 e $30 \mathrm{~cm}$; assim, quando o potencial matricial da água no solo da parcela sem déficit hídrico atingia $-20 \mathrm{kPa}$, irrigava-se, aplicando-se uma lâmina que restabelecesse a condição de capacidade de campo, pois o potencial da água no solo favorável à produção máxima da batata situa-se acima de $-30 \mathrm{kPa}$ (Yadav \& Tripathi, 1973). Os valores da umidade no solo, no momento das irrigações, foram obtidos das curvas características de água no solo, nas profundidades de 10 e $30 \mathrm{~cm}$, a partir dos valores de potencial da água.

As evapotranspirações real e máxima da cultura foram estimadas a partir do balanço hídrico, com fundamento na lei da conservação das massas (Reichardt, 1985). Considerou-se um volume de solo de $40 \mathrm{~cm}$ para as determinações dos componentes do balanço hídrico da cultura, profundidade esta que abrange o máximo do sistema radicular da batata (Rab \& Willatt, 1987). Foi usada, em cada parcela, uma bateria de tensiômetros com manômetros de mercúrio nas profundidades de 10, 30, 50 e 70 cm para medidas dos potenciais matriciais da água no solo. As leituras foram feitas diariamente, até as 8 horas da manhã. Nas condições em que se conduziu o trabalho, os componentes precipitação e escoamento superficial do balanço hídrico foram negligenciados, uma vez que as parcelas foram protegidas contra as chuvas e, também, sistematizadas a nível e com bordos para evitar o escoamento superficial da água de irrigação. O balanço hídrico teve início a partir de 15 dias após 
a emergência, para que a fase de estabelecimento da cultura não apresentasse problemas e foi realizado nos três estádios fenológicos em estudo.

O plantio foi realizado no dia 27 de agosto, em sulcos distanciados $0,8 \mathrm{~m}$. As batatas-semente foram distribuídas em sulcos de aproximadamente $0,07 \mathrm{~m}$ de profundidade, manualmente, no espaçamento de $0,35 \mathrm{~m}$, em conjunto com o inseticida Temik 10 e, em seguida, cobertas por solo de um sulco aberto ao lado, onde foram distribuídos os adubos e, depois, misturados à terra com um sulcador manual. A adubação de plantio comum a todas as parcelas correspondeu a $60 \mathrm{~kg} \cdot \mathrm{ha}^{-1} \mathrm{de}$ $\mathrm{N}$, a 240kg.ha- ${ }^{-1}$ de $\mathrm{P}_{2} \mathrm{O}_{5}$ e $120 \mathrm{~kg} \cdot \mathrm{ha}^{-1}$ de $\mathrm{K}_{2} \mathrm{O}$, recomendação para solos com teores médios e altos de $\mathrm{Pe} \mathrm{K}$, respectivamente. As doses de $\mathrm{P}_{2} \mathrm{O}_{5}$ e $\mathrm{K}_{2} \mathrm{O}$ foram aplicadas no plantio, e a de $\mathrm{N}$ foi parcelada, sendo metade aplicada na ocasião do plantio e a outra 35 dias após a emergência, durante a operação de amontoa.

As parcelas foram irrigadas, do plantio até o início da aplicação dos tratamentos, por um sistema convencional de irrigação por aspersão. Neste período foi aplicada uma lâmina média total de $65,9 \mathrm{~mm}$, com freqüência média de 5 dias. Aos quinze dias após a emergência, verificou-se a uniformidade do estande ocasionando, então, a aplicação dos tratamentos, sendo a água aplicada por um equipamento em forma de $\mathrm{T}$ feito de PVC rígido de 1/2 polegada de diâmetro, com furos de 1/16 polegada para sair a água, distanciados de $2 \mathrm{em} 2 \mathrm{~cm}$, com um hidrômetro de vazão máxima $1,5 \mathrm{~m}^{3} \cdot \mathrm{h}^{-1}$ e resolução de $0,0001 \mathrm{~m}^{3}$, para melhor controle do volume de água aplicado às parcelas.

Durante o ciclo da cultura foram realizadas duas capinas manuais com amontoa, para favorecer o desenvolvimento das plantas. Para controle das pragas e doenças foram feitas aplicações semanais com os defensivos agrícolas Methamidophos e Mancozeb, enquanto nas colheitas, realizadas manualmente aos 81 dias após emergência, os tubérculos colhidos da área útil foram pesados e classificados de acordo com o diâmetro transversal, como: graúdo, > 45mm; média, de 33 a 45mm; miúda, de 23 a 33mm e miudinha, de 20 a $23 \mathrm{~mm}$. Para avaliação dos resultados foram consideradas produção por classe de tamanho de tubérculos e número de tubérculos por planta, que foram submetidos à analise da variância, conforme Gomes (1970) e os valores médios comparados pelo teste de Tukey, a nível de $5 \%$ de probabilidade.

\section{RESULTADOS E DISCUSSÃO}

Os resultados relativos à evapotranspiração acumulada, à produtividade da batata e ao número de tubérculos por planta, obtidos nos oito tratamentos, são apresentados na Tabela 3.

\section{Evapotranspiração e produtividade}

A análise de variância nas produtividades constatou diferença estatística significativa $(\mathrm{p}<0,05)$ entre as produtividades médias dos tratamentos (Tabela 3 ). O tratamento que sofreu déficit apenas no estádio de enchimento de tubérculos e o que sofreu déficit nos estádios vegetativo e de enchimento de tubérculos, apresentaram resultados estatisticamente iguais, enquanto os outros os apresentaram distintos entre si.

O tratamento em que foi mantida a condição ótima de suprimento de água durante o ciclo da cultura originou a evapotranspiração máxima (ETm) e a produtividade máxima da batata. As irrigações foram realizadas quando a umidade do solo atingia o valor limite médio de $26,2 \%$, representando um consumo médio de aproximadamente $20 \%$ da água disponível do solo, portanto em condição de umidade favorável, visando alcançar a produtividade máxima (Islam et al., 1990; Steyn et al., 1992).

No tratamento em que apenas na fase de enchimento de tubérculos ocorreu déficit, este foi de $61,1 \mathrm{~mm}$ em 26 dias,

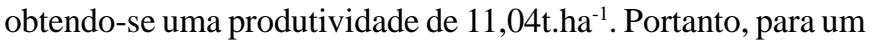
déficit de evapotranspiração de $52,1 \%$ no estádio de enchimento de tubérculos, houve redução média de 10,47t.ha-1 (Tabela 3) originando uma produtividade de $51,3 \%$ no tratamento em que não houve déficit, o que evidencia a importância do suprimento adequado da água nesse estádio. Os resultados obtidos confirmam as observações de Doorenbos \& Kassam (1979), Ojala et al.(1990) e Stark \& McCann (1992) de que se deve evitar déficit de água nesse estádio fenológico, a fim de não comprometer a produtividade da batata.

Verificou-se, no tratamento onde houve déficit apenas no estádio de tuberização, um déficit de evapotranspiração de $26,5 \mathrm{~mm}$ em 18 dias e, também, produtividade de 8,63t.ha- ${ }^{-1}$. A redução de $39,3 \%$ da evapotranspiração no estádio de tuberização causou uma redução média de $12,88 \mathrm{t} \cdot \mathrm{ha}^{-1}$ de produção, equivalente a $40,1 \%$ da produtividade, obtida quando as plantas não foram expostas a nenhum déficit (Tabela 3) indicando a necessidade de um manejo adequado de água nesse estádio. Hukkeri \& Sharma (1979) também verificaram que a redução na produção causada por déficit hídrico nesse estádio (tuberização) é bem maior que em outros estádios de desenvolvimento da batata.

Tabela 3. Valores médios da evapotranspiração acumulada, em $\mathrm{mm}$, relativos a cada estádio fenológico, de produtividade, em t.ha ${ }^{-1}$, e número de tubérculos/planta $\left(\right.$ NT.P $\left.^{-1}\right)$ obtido nos tratamentos, Piracicaba, SP

\begin{tabular}{|c|c|c|c|c|c|c|}
\hline \multirow{3}{*}{ Tratamentos } & \multirow{2}{*}{\multicolumn{4}{|c|}{$\begin{array}{c}\text { Evapotranspiração(mm) } \\
\text { Estádios fenológicos }\end{array}$}} & \multirow{3}{*}{$\begin{array}{l}\text { Produtividade } \\
\qquad\left(\text { t.ha }^{-1}\right)\end{array}$} & \multirow{3}{*}{ NT.P $\mathrm{P}^{-1}$} \\
\hline & & & & & & \\
\hline & 1 & 2 & 3 & Total & & \\
\hline $\mathrm{T}_{1}$ & 45,6 & 67,5 & 117,2 & 230,0 & $21,51 \mathrm{a}$ & $9,5 \mathrm{a}$ \\
\hline $\mathrm{T}_{2}$ & 46,7 & 70,2 & 56,1 & 173,0 & $1,04 d$ & $5,7 \mathrm{de}$ \\
\hline $\mathrm{T}_{3}$ & 45,8 & 41,0 & 123,7 & 210,5 & $8,63 \mathrm{f}$ & $5,6 \mathrm{def}$ \\
\hline $\mathrm{T}_{4}$ & 45,8 & 46,7 & 53,4 & 145,9 & $7,44 \mathrm{~g}$ & $6,2 \mathrm{~cd}$ \\
\hline $\mathrm{T}_{5}$ & 34,3 & 71,2 & 125,9 & 231,4 & $18,45 b$ & $8,5 \mathrm{ab}$ \\
\hline $\mathrm{T}_{6}$ & 36,2 & 80,8 & 58,8 & 175,8 & $10,44 d$ & $5,2 \mathrm{defg}$ \\
\hline $\mathrm{T}_{7}$ & 37,5 & 40,2 & 118,8 & 196,5 & $12,63 \mathrm{c}$ & $7,2 \mathrm{bc}$ \\
\hline $\mathrm{T}_{8}$ & 35,6 & 35,7 & 52,6 & 123,9 & $6,34 \mathrm{~h}$ & $4,4 \mathrm{efh}$ \\
\hline Média & 40,9 & 56,7 & 88,3 & 185,9 & 12,06 & 6,5 \\
\hline C.V. (\%) & 4,2 & 8,3 & 4,3 & 9,2 & 5,29 & 14,6 \\
\hline
\end{tabular}

Em cada produtividade e número de tubérculos por planta, médias seguidas pela mesma letra não diferem entre si, entre os tratamentos

1,2,3, - Estádios fenológicos vegetativo, de tuberização e de enchimento de tubérculos, respectivamente

No tratamento com déficit na tuberização e enchimento de tubérculos, o déficit de evapotranspiração foi de $20,8 \mathrm{~mm}$ em 18 dias para a tuberização e de $63,8 \mathrm{~mm}$ em 26 dias, para o enchimento de tubérculos, resultando em uma produtividade média de 7,44t.ha-1 da batata (Tabela 3 ) que representou apenas $34,6 \%$ da produção obtida no tratamento sem déficit. 
No tratamento com déficit apenas no estádio vegetativo, o déficit de evapotranspiração foi de $11,3 \mathrm{~mm}$, resultando em uma produtividade média de 18,45 t.ha $^{-1}$. O déficit de $24,8 \%$ na evapotranspiração máxima neste período causou redução média da produtividade, de 14,2\% em relação ao tratamento sem déficit (Tabela 3) demonstrando, portanto, que o déficit neste período pode não resultar em grandes perdas de produção; mesmo assim, deve-se considerar que o déficit hídrico foi imposto a partir da segunda metade desse estádio, para que a fase de estabelecimento da cultura não apresentasse problemas; além disso, devido à imposição do déficit a partir dos 15 dias após a emergência, durante um pequeno período até o final do estádio, o seu grau foi relativamente pequeno, mas estudos realizados por Miller \& Martin (1987) e Doorenbos \& Kassam (1979) confirmam as conclusões de que a redução ou suspensão das irrigações no estádio vegetativo pode não resultar em grandes perdas de produção de batata.

No tratamento com déficit nos estádios vegetativo e enchimento de tubérculos, o déficit de evapotranspiração foi de $9,4 \mathrm{~mm}$ em 16 dias no vegetativo e de $58,4 \mathrm{~mm}$ em 27 dias no enchimento de tubérculos, resultando na produtividade média de 10,44t.ha ${ }^{-1}$. Portanto, déficit em termos de evapotranspiração parcial de $20,6 \%$ no estádio vegetativo e de $49,8 \%$ no estádio de enchimento de tubérculos, gerou redução na produção de tubérculos por hectare, da ordem de 11,07 toneladas, ou 51,5\% de redução em relação ao tratamento sem déficit (Tabela 3) confirmando a importância do estádio de enchimento de tubérculos onde ocorreu o maior déficit. Resultados idênticos também foram observados em Idaho, por Larsen (1982) com as cultivares Russet Burbank, Russet Lemki e Russet Nooksack e Stark \& McCann (1992) com a cultivar Russet Burbank.

No tratamento com déficit nos estádios vegetativo e de tuberização, a produtividade obtida foi de 12,63 tha $^{-1}$. O déficit de evapotranspiração, de 17,8\% no estádio vegetativo e de 40,4\% na tuberização, causou redução na produtividade, de 8,88 t.ha $^{-1}$ ou $41,3 \%$ de redução, em relação ao tratamento sem déficit (Tabela 3).

No tratamento com déficit nos três estádios, a evapotranspiração atual acumulada média, das quatro repetições, foi de $35,6 \mathrm{~mm}$ no estádio vegetativo, de $35,7 \mathrm{~mm}$ no estádio de tuberização e de $52,6 \mathrm{~mm}$ no estádio de enchimento de tubérculos, que corresponderam, respectivamente, a 78,1\%, $52,9 \%$ e $44,9 \%$ da evapotranspiração máxima do tratamento sem déficit, nos respectivos estádios fenológicos. A produtividade nesta condição foi de 6,34 tha $^{-1}$ ou $70,5 \%$ de redução em relação ao tratamento sem déficit (Tabela 3).

\section{Tamanho de tubérculos}

As porcentagens médias de tubérculos para os oito tratamentos, por classe de tamanho do diâmetro transversal, são mostradas na Tabela 4. As maiores porcentagens de tubérculos graúdos (diâmetro $>45 \mathrm{~mm}$ ) foram obtidas nos tratamentos caracterizados por não sofrerem déficit hídrico nos estádios de tuberização e enchimento de tubérculos. A menor porcentagem de tubérculos graúdos e a maior de tubérculos de menor diâmetro foram verificadas nos tratamentos onde o déficit ocorreu nos estádios de tuberização ou enchimento de tubérculos. Constatase que o estresse hídrico aumentou a percentagem de tubérculos de tamanho médio e pequeno, conforme já verificado por Segóvia et al. (1972), Dar \& Rosário ( 1981) e Sood ( 1986) que constataram aumento da produção de tubérculos das classes de diâmetro entre 23 a $33 \mathrm{~mm}$ e entre 20 a $23 \mathrm{~mm}$ devido ao estresse hídrico.

Tabela 4. Porcentagem de tubérculos por classse de tamanho do diâmetro transversal obtido nos tratamentos

\begin{tabular}{cllcc}
\hline \multirow{2}{*}{ Tratamentos } & \multicolumn{4}{c}{ Porcentagem de tubérculos } \\
\cline { 2 - 5 } & Graúdo & Média & Miúda & Miudinha \\
\hline 1 & $49 \mathrm{a}$ & $36 \mathrm{bcd}$ & $15 \mathrm{~b}$ & $1 \mathrm{~b}$ \\
2 & $22 \mathrm{~d}$ & $55 \mathrm{a}$ & $21 \mathrm{~b}$ & $2 \mathrm{~b}$ \\
3 & $21 \mathrm{~d}$ & $50 \mathrm{abc}$ & $24 \mathrm{~b}$ & $5 \mathrm{~b}$ \\
4 & $19 \mathrm{~d}$ & $38 \mathrm{~d}$ & $31 \mathrm{a}$ & $12 \mathrm{a}$ \\
5 & $41 \mathrm{~b}$ & $39 \mathrm{bcd}$ & $19 \mathrm{~b}$ & $1 \mathrm{~b}$ \\
6 & $37 \mathrm{~b}$ & $45 \mathrm{abcd}$ & $17 \mathrm{~b}$ & $1 \mathrm{~b}$ \\
7 & $32 \mathrm{bcd}$ & $47 \mathrm{abcd}$ & $19 \mathrm{~b}$ & $2 \mathrm{~b}$ \\
8 & $28 \mathrm{~cd}$ & $50 \mathrm{~b}$ & $23 \mathrm{~b}$ & $3 \mathrm{~b}$ \\
\hline CV $(\%)$ & 16,95 & 13,43 & 17,01 & 13.98 \\
\hline
\end{tabular}

Em cada classe de tamanho de tubérculos, médias seguidas pela mesma letra não diferem entre si, entre os tratamentos.

\section{Número de tubérculos por planta}

Os números médios de tubérculos por planta $\left(\mathrm{NT}^{\left.-\mathrm{P}^{-1}\right)}\right.$ para os tratamentos são apresentados na Tabela 3. Verificou-se diferença estatística significativa $(\mathrm{p}<0,05)$ nos números de tubérculos por planta, com a aplicação dos tratamentos. O maior NT.P ${ }^{-1}$ foi encontrado no tratamento caracterizado por apresentar suprimento adequado de água nos três estádios, seguido do tratamento que recebeu suprimento adequado de água nos estádios de tuberização e enchimento dos tubérculos. O menor NT.P ${ }^{-1}$ ocorreu no tratamento caracterizado por estar sob deficiência hídrica nos três estádios fenológicos. Os resultados são coerentes com as observações de Miller \& Martin (1987) e Miller \& Martin (1990) mas discordam com as observações de Segóvia et al. (1972); Dar \& Rosário(1981); Zaag \& Demagante (1985) e Duarte (1989) que não constataram diferenças estatísticas significativas entre o número de tubérculos por planta com a aplicação do estresse hídrico.

\section{CONCLUSÕES}

Em decorrência dos resultados obtidos, pode-se concluir o seguinte:

1. A ocorrência de déficit hídrico no estádio de tuberização causou uma drástica redução na produtividade. Este estádio foi considerado o mais crítico ao déficit hídrico.

2. A deficiência hídrica em dois estádios fenológicos provocou maior redução na produtividade de tubérculos, quando aplicada nos estádios de tuberização e enchimento de tubérculos. O déficit hídrico aplicado nos três estádios fenológicos causou a maior redução de produtividade.

3. O déficit hídrico afetou significativamente a produção total de tubérculos e o número de tubérculos por planta. 
4. O tamanho dos tubérculos foi afetado pelo estresse hídrico. Maiores percentagens de tubérculos graúdos foram obtidas nos tratamentos que não sofreram déficit no estádio de enchimento de tubérculos.

\section{REFERÊNCIAS BIBLIOGRÁFICAS}

CUNHA, G.R.; BERGAMASCHI, H. Efeitos da disponibilidade hídrica sobre o rendimento das culturas. In: BERMASCHI, H. Agrometeorologia aplicada à irrigação. Porto Alegre: UFRGS, 1992. cap. 6, p.85-96.

DAR, W.D. ; ROSÁRIO, D.A. DEL Response of white potato (Solanum tuberosum L.) to moisture stress. Philippine Agriculture, v. 64, n.2, p.125-134, 1981.

DOORENBOS, J.; KASSAM, A.H. Efectos del agua sobre el rendimiento de los cultivos, FAO, 1979. 212p. (Riego drenage, 33).

DUARTE, S.N. Efeitos do horário e da lâmina de irrigação na cultura da batata (Solanum tuberosum $\mathrm{L}$.). Piracicaba: ESALQ, 1989. 148p. Dissertação de Mestrado.

GOMES, F.P. Curso de estatística experimental. 13 ed. Piracicaba: Nobel, 1970. 468p.

HUKKERI, S.B. ; SHARMA, A.K. Tailoring the irrigation schedule for higher water - use efficiency in potato production. Indian Journal of Agricultural Sciences, v.49, n.5, p.336-339, 1979.

ISLAM, T.; STARKER, H.; ALAM, J.; HARUN-UR-RASHID, M. Water use and yield relationships of irrigated potato. Agricultural Water Management, v.18, n.2, p.173-179, 1990.

JANA, P.K.; DAS, S.; MANDAL, B.B.; BANDYOPADHYAY, P. Effect of soil moisture tension at different physiological stages of growth on yield and consumptive use of water by potato. Environment and Ecology, v.7, n.4, p.809-812, 1989.

KLEINKOPF, G.E. Potato. In: TEARE, J. D., PEET, M. M. Crop water relations. Idaho: Wiley \& Sons, 1983. cap. 9, p.287-305.

LARSEN, D.C. Simplifying potato irrigation scheduling the Idaho program. American Potato Journal, v.61, n.4, p.215-227, 1982.

LOON, C.D. VAN. The effect of water stress on potato growth, development and yield. American Potato Journal, v.58, n.1, p.51-69, 1981.
MILLER, D.E.; MARTIN, M.W. The effect of irrigation regime and subsoiling on yield and quality of three potato cultivars. American Potato Journal, v.64, n.1, p.17-25, 1987.

MILLER, D.E.; MARTIN, M.W. Responses of three early potato cultivares to subsoiling and irrigation regime on a sandy soil. American Potato Journal, v.67, n.11, p.769-777, 1990.

OJALA, J.C.; STARK, J.C.; KLEINKOPF, G.E. Influence of irrigation and nitrogen management on potato yield and quality. American Potato Journal, v.67, n.1, p.29-43, 1990.

RAB, M.A. ; WILLATT, S.T. Water use by irrigated potatoes on a duplex soil. Australian Journal of Experimental Agriculture, v.27, n.1, p.165-172, 1987.

RANZANI, G.; FREIRE, O.; KINJO, T. Carta de solos do município de Piracicaba. Piracicaba: Centro de Estudos de Solos/ESALQ/USP, 1966. 85p.

REICHARDT, K. Processo de transferência no sistema soloplanta-atmosfera. 4.ed. Campinas: Fundação Cargill, 1985. 466p.

SEGÓVIA, F.C.; SILVA, J.F.; BERNARDO, S.; CONDÉ, A.R. Efeito do sistema de plantio e da frequência de irrigação sobre a cultura da batata ( Solanum tuberosum L. ). Revista Ceres, Viçosa, v.19, n.105, p.328-346, 1972.

SOOD, M.C. Effect of supplemental irrigation, mulching and nitrogen levels on growth, yield and nutrients uptake of potatoes in Shimla hills. Indian Journal of Agricultural Sciences, v.56, n.1, p.47-55, 1986.

STARK, J.C.; McCANN, I.R. Optimal allocation of limited water supplies for Russet Burbank potatoes. American Potato Journal, v. 69, n.7, p.413-421, 1992.

STEYN, J.C.; PLESSIS, H.F. du.; NORTJE, P.F. The effect of different water regimes on Up-to-date potatoes. I. Vegetative development, photosynthetic rate and stomatal diffusive resistence. South African Journal of Plant and Soil, v.9, n.3, p.113-117, 1992.

YADAV, S.C.; TRIPATHI, B.R. Water requirement of potato. Indian Journal of Agricultural, v.43, n.5, p.477-482, 1973.

ZAAG, P.V.; DEMAGANTE, A. Water requirements as influenced by irrigation system and mulch for potato (Solanum spp.) grown in an isohyperthermic environment in the Philippines. The Philippine Agriculturist, v.80, n. 4, p.571-584, 1985. 